\title{
Hastalıklar Verimlilik ve Ulusal Gelir Arasındaki Nedensellik İlişkilerinin Analizi: 'Türkiye'de Kanser Örneği
}

\author{
Pınar KOÇ ${ }^{1}$
}

Öz

Ölümcül hastalıklar beşeri emek stokunu azaltıcı etkiler yaratırken, emek verimliliği kanalıyla beşeri sermaye stokunu nitelik bakımından da negatif etkilemektedir. Ayrıca hastalıkların tedavisi için ayrılan kaynak miktarının artması, daha üretken alanlara yapılabilecek yatırım olanaklarını azaltarak etkin kaynak dağılımını bozucu etkiler yaratmaktadır. Bu bağlamda 1990-2017 dönemini kapsayan bu çalışmanın amacı; kanser örneği ele alınarak, hastalıklar, emek verimliliği ve ulusal gelir arasındaki nedensellik ilişkilerini analiz etmektir. Çalışmada simetrik ve zamanla değişen simetrik nedensellik testleri kullanılmıştır. Kanserli hasta sayısı, emek verimlilik endeksi ve kişi başına düşen gelir düzeyi çalışmada kullanılan değişkenlerdir. Simetrik nedensellik testi sonuçlarına göre kanserli hasta sayısı ile emek verimliliği ve kişi başına düşen gelir arasında nedensellik ilişkisi yoktur. Ancak zamanla değişen simetrik nedensellik testi sonuçlarına göre 1990-2006 ve 1998-2014 dönemlerinde kanserli hasta sayısı ile ulusal gelir arasında; 1992-2008 ve 2000-2016 yıllarında kanserli hasta sayısı ile verimlilik arasında nedensellik ilişkisi vardır. Kanserli hasta sayısı ile verimlilik ve ulusal gelir düzeyi arasında eş anlı nedenselliğin görüldüğü yıllar 2000-2014 yıllarıdır

Anabtar Kelimeler: Emek Verimliliği, Kanserli Hasta Sayısı, Simetrik Nedensellik, Ulusal Gelir.

The Causality Analysis of the Relationship between Diseases, Productivity and National Income: The Example of Cancer in Turkey

\begin{abstract}
Mortal diseases negatively affect the human capital stock in terms of quality through labor productivity while they have a negative effect on the labor stock due to their mortally. In addition to this, the increase in the amount of resources allocated for the treatment of diseases may have an effect on disrupting the efficient distribution of resource by reducing the investment opportunities in more productive areas. In this context, the purpose of this study is to analyze the causality relationships between diseases, labor productivity and the national income for the period of 1990-2017. Symmetric Causality Test and Time Varying Causality Test were used in the study. The number of cancer patients, labor productivity index and per capita income are variables used in the model. According to results of Symmetric Causality Test, there is no causality relationship between the number of cancer patient, labor productivity and the per capita income. But, According to results of Time Varying Symmetric Causality Test, there is causality relationship between the numbers in periods of 1990-2006 and 1998-2014 and there is causality relationship between the number of cancer patient and labor productivity periods of 1992-2008 and 20002016. The period of 2000-2014 are periods when there is a simultaneous causality between the number of cancer patient, the labor productivity and the per capita national income.
\end{abstract}

Key Words: Labor Productivity, Thenumber of cancerpatient, Symmetriccausality, Thenationalincome

Atıf İçin / Please Cite As:

Koç, P. (2020). Hastalıklar verimlilik ve ulusal gelir arasındaki nedensellik ilişkilerinin analizi: Türkiye'de kanser örneği. Manas Sosyal Araştırmalar Dergisi, 9(3), 1855-1862.

Geliş Tarihi / Received Date: 25.10.2019

Kabul Tarihi / Accepted Date: 22.04.2020

1Dr. Öğretim Üyesi-Gümüşhane Üniversitesi İktisadi ve İdari Bilimler Fakültesi, pinartorun@gumushane.edu.tr ORCID0000-0002-7843-1228 


\section{Giriş}

Hem kaynak dağlımı hem de ekonomik karar birimleri üzerindeki etkileri bakımından hastalıkların makroekonomik ve mikroekonomik etkileri hastallkların ekonomik maliyetleri literatürü kapsamında incelenmektedir. İlgili literatür kapsamında hastalık maliyetleri doğrudan ve dolaylı maliyetler olmak üzere ikiye ayrılmaktadır. Doğrudan maliyetler; hastalıkların tedavisi için ayrılan her türlü parasal kaynak miktarını ifade ederken, hastalıkların emek verimliliğini azaltarak bireysel üretim ve ulusal gelir düzeyi üzerindeki negatif etkileri dolaylı maliyetleri kapsamaktadır. Bu bağlamda ülke düzeyinde hastalık yükü araştırmaları yapılmaktadır.

Türkiye'de kanser insidansının ve kanser prevalansının her geçen arttı̆̆1 görülmektedir. Sağlık Bakanlığı tarafindan yapılan araştırmalara göre, koruyucu sağlık önlemleri alınmadığı sürece 2030'lu yıllarda sadece kanser tedavisi için yapılan harcamaların Sağlık Bakanlığı bütçesi ile karşılanamayacak boyutlara ulaşması beklenmektedir. Türkiye'de kanserin doğrudan maliyetleri ile ilgili çalışmalar yapılmış, ancak kanserin dolaylı etkileri ile ilgili çalışma sayısının sınırlı olduğu görülmüştür. Bu bağlamda bu çalışmada kanserli hasta sayısı ile emek verimliliği ve ulusal gelir düzeyi arasındaki nedensellik ilişkileri analiz edilmiştir. Çalışmada öncelikli olarak hastalıklar ile ulusal gelir arasındaki etkileşim mekanizmaları incelenmiş, daha sonra ilgili literatür incelenerek, tahmin sonuçları sunulmuştur.

\section{Hastalıklar, Emek Verimliliği ve Ulusal Çıktı Düzeyi}

Hastalıklar; yaşam beklentisindeki azalma, bebek ve çocuk ölümlerinin artması nedeniyle çocuk yatırımlarının azalması ve bireysel emek verimliliğindeki azalma kanalıyla ulusal gelir düzeyini olumsuz etkilemektedir (World Bank, 2001). Hastalık yükündeki artışlara bağlı olarak morbidite ve mortalite oranlarındaki artış, yaşam beklentisinde azalmalara neden olmaktadır. Cuddington (1993) morbidite oranlarındaki artışların, bireylerin sağlık harcamalarını artırarak, sağlık dışı mal ve hizmet tüketimini azaltacağını ve bireylerin tasarruf davranışlarını değiştireceğini ve dolayısıyla ulusal gelir düzeyini azaltacağını vurgulamaktadır.

Hastalıklar beşerî sermaye birikimi ve eğitim düzeyi üzerinde de negatif etkiler yaratmaktadır. Eğitim beşerî sermayenin temel belirleyicidir. Bununla birlikte, sağlık düzeyi de eğitim seviyesi ve derse katılım oranlarını önemli ölçüde etkilemektedir. Hastalıklar öğrencilerin bilişsel fonksiyonlarını negatif etkileyerek, beşerî sermaye stokunda azalmaya neden olacaktır (Bloom ve Canning, 2008). Bu bağlamda hastalık yükündeki artışların, cari dönemde emek verimliliğini negatif etkilerken, eğitim kanalityla gelecek dönem beşerî sermaye stokunu da negatif etkilemesi beklenmektedir.

Hastalıkların emek verimliliğinde neden olacağı değiş̧me, firma geliri ve karlllık düzeyi üzerinde de negatif etkiler yaratabilir.

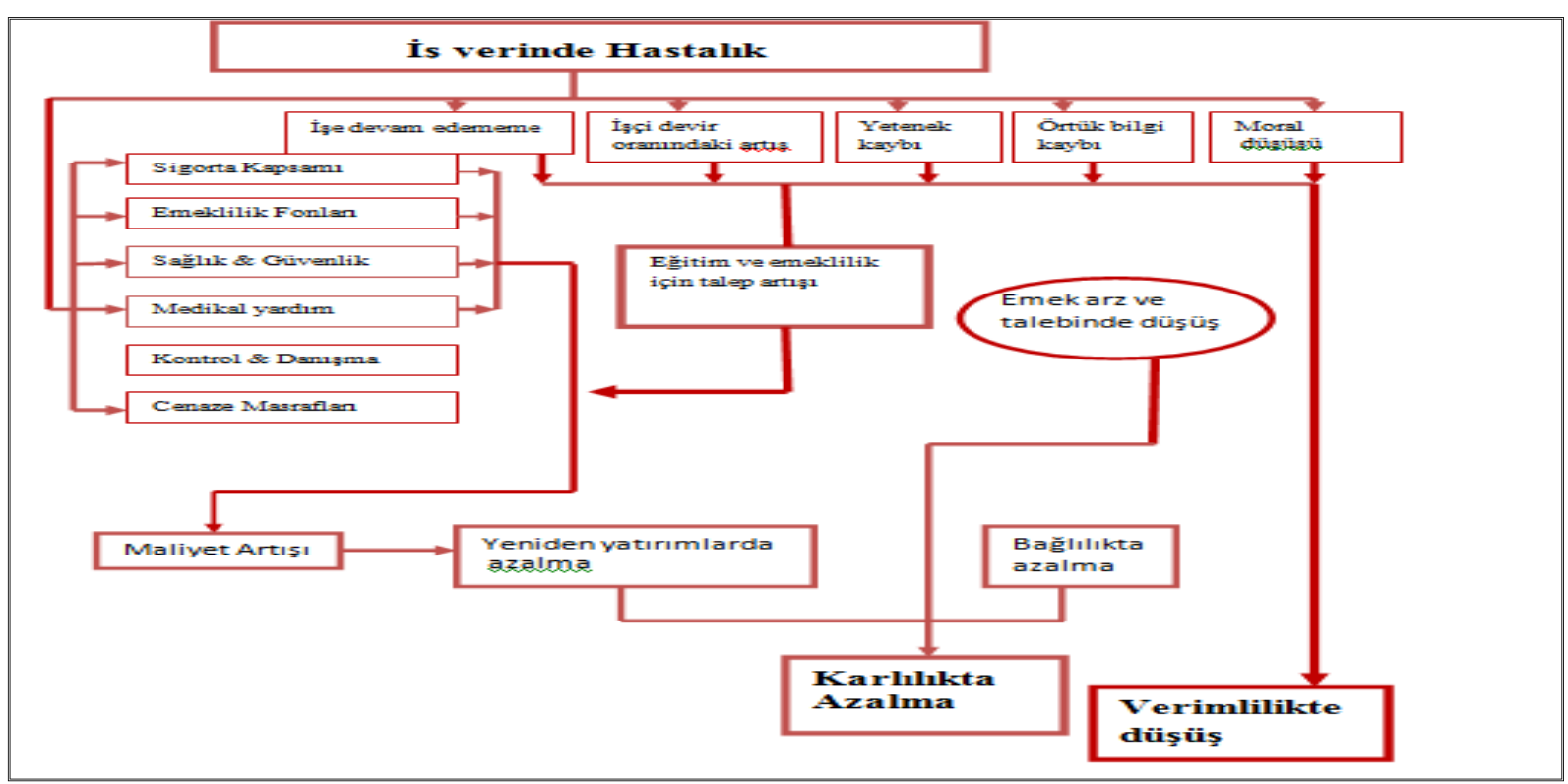

Şekil 1. Hastalıklarn Firmalar Üz̧erindeki Etkileri (Dab, 2000, s. 15) 
Daly (2000) hastalıkların firma maliyetleri üzerindeki etkilerini incelemiştir. Hastalıklar, işgücünün işe devam durumunu, işçi devir oranını, çalışma bilgi ve kabiliyetini ve çalışma motivasyonunu negatif etkileyecektir. Bu durum emek verimliliğinde azalmaya ve emek arzında düşmeye neden olmaktadır. Hastalık nedeniyle işçilerin işten ayrılma talebinde bulunması, firmanın yeni işçiler için ayırdı̆̆ı eğitim masraflarını ve sağılı ve güvenlik harcamalarını artırarak firma maliyetlerinin artmasına, yeniden yatırımların azalmasına neden olarak karlılık düzeyini de olumsuz etkilemektedir. Hastalıkların tedavisi için ayrılan kaynak miktarındaki artışn, bireye ve firmaya ne kadar maliyet yükleyeceği, ülkedeki sağlık sigortalarının gelişmişlik düzeyine ve sağlık sigortasının kapsamına bağlıdır.

Afsa ve Givord (2002) ile Case ve Deaton (2005) sağlık statüsünün bireyin işe devam durumu üzerindeki etkilerini analiz etmiştir. Sağlık statüsüne bağlı olarak, hastalık için yapılan harcama düzeyi ve buna bağlı olarak bireyin tüketim olanaklarında meydana gelen değişme, çalışanların işe devam durumunu önemli ölçüde etkilemektedir.

Hastalıkların çalışanların bilgi ve çalışma kabiliyeti ve çalışma motivasyonunu olumsuz etkilemesi, emek arzını olumsuz etkilerken, firma için yeni bir işçinin işe alınması ve işçinin eğitilmesi için ayırdığ1 kaynak miktarının artması da firma maliyetlerini artırmaktadır. Bu bağlamda hastalıklar, firmanın üretim düzeyiyle birlikte firma karlllı̆̆ üzerinde negatif etkiler yaratabilmektedir.

\section{Literatür Taraması}

Uluslararası literatürde hastalıkların doğrudan ve dolaylı maliyetleri ile ilgili çok sayıda çalışma yapılmıştır. Stenier, Tia, Main ve Bradley (2004), Arozullah vd. (2004), Amir, Moran, Wals, Iddenden ve Luker (2007), Mahal, Karan, Fan ve Engelgau (2013), Ekwueme, Trogdon, Khavjou ve Guy (2014), Hanly, Timmons, Walsh ve Sharp (2012), Hanly ve Sharp (2014), Venkatesan (2018) ve Pearce vd. (2018) tarafindan yapılan çalışmalar özellikle son dönemde kanserin neden olduğu verimlilik ve çıktı düzeyi kayıplarını analiz eden çalışmalardır. Elde edilen sonuçlara göre kanser, işçilerin çalışma düzeylerini ve emek başına düşen çıtı düzeyini negatif etkilemektedir.

Amir vd. (2007) kanserden kaynaklanan iş tahmin kaybının \%51 olduğu sonucuna ulaşırken, Mahal vd. (2012) Hindistan için yaptığı çalışmada kanser insidansındaki artışların işgücüne katıllım oranlarını ve hane halklarının tüketim ve tasarruf davranışlarını olumsuz etkilediği sonucuna ulaşmıştır. Hanly vd. (2014) tarafindan yapılan çalışmaya göre İrlanda'da kanserle nedeniyle gerçekleşen erken ölümlerin toplam maliyeti 509.5 milyon $€$ iken, Vantekasan (2018) tarafından yapılan çalşsmaya göre, BRICS ülkelerinde kanser ölümlerinden kaynaklanan verimlilik kaybı maliyeti 46.3 milyar dolardır.

Ekwueme vd. (2014) ABD'de kanser tedavi maliyetleri ve kanserden kaynaklanan verimlilik kayıplarını analiz etmiştir. Çalışmadan elde edilen sonuçlara ABD'de toplam kanserin tedavi maliyetleri ve verimlilik kaybı maliyetlerinin toplamı 2011 dolardır.

Türkiye'de kanserin dolaylı maliyetlerini inceleyen çalısmalar mevcuttur. Ancak kanserin dolaylı maliyetlerini inceleyen çalışma sayısı sınırlıdır. Ertan (2003), Çakır Edis ve Karlıkaya (2007), Koçkaya vd. (2013) tarafindan yapılan çalışmalarda kanser tedavi maliyetlerini hesaplanırken, Yazıhan ve Yılmaz (2007), Özmen vd. (2017) kanser taramalarının yapılması durumunda kanser tedavi masraflarından elde edilecek tasarruf miktarlarını, Yılmaz vd. (2009) kanserle mücadele politikalarının başarılı olması durumunda elde edilecek tasarruf miktarlarını analiz etmiştir. Son olarak Torun ve Kutlar (2018) hesaplanabilir genel denge modelini kullanarak kanserin neden olduğu sektörel çıktı kaybını analiz etmiştir.

Ertan (2003) kanserin tanı ve tedavisi için yapılan toplam harcama ve kişi başına harcama miktarlarını tahmin etmişti. Çalışmadan elde edilen sonuçlara göre, kanserin tanı ve tedavisi için yapılan toplam harcama 830 Milyar TL iken, kişi başına düşen harcama miktarı 11.36 Milyar TL'dir. Çakır Edis ve Karlıkaya (2007) akciğer kanserinin maliyetlerini incelemiştir. Çalışmadan elde edilen sonuçlara göre hasta başına ortalama tedavi maliyeti 4.088 dolar ile 5480 dolar arasında değişmektedir.

Koçkaya vd. (2013) Kolon kanserinin tedavi maliyetlerini incelediği çalışmasında yaşam beklentisine dayalı en düşük maliyetin 5.359 olduğu sonucuna ulaşmıştır. Yazıhan ve Yılmaz (2007) tarafindan yapılan çalışmaya göre, iki yılda bir kanser taraması yapılması durumunda kanser tedavi maliyetlerinden elde edilecek tasarrufun yaklaşık 218 milyon TL'dir. Özmen vd. (2017) kanser taramalarının kaynak ve maliyet etkinliğini artırıcı etkiler yaratacağını ortaya koymuştur. Torun ve Kutlar (2018) tarafindan yapılan çalşmaya göre kanser ilaçları için SGK tarafindan yapılan toplam ödeme 458 Milyon TL'dir. Bununla 
birlikte kanser emek verimliliğini \% 0.01 azaltmaktadır. Kanser nedeniyle meydana gelen çıktı kaybı, verimlilik kaybından daha fazladır.

\section{Yöntem ve Veri Seti}

1990-2017 dönemini kapsayan bu çalısmada kanserli hasta sayısı ile emek verimliliği ve kişi başına düşen hasıla düzeyi arasındaki nedensellik ilişkileri analiz edilmiştir. Kanserli hasta sayıları dünya kanser araştırma fonu istatistiklerinde elde edilmiştir. Emek verimliliği göstergesi olarak çalışma saati başına düşen çıktı düzeyi kullanılmıştır. Çalışma saati başına düşen çıktı düzeyleri ve kişi başına düşen ulusal gelir istatistikleri OECD veri tabanından elde edilen istatistiklerdir. Nedensellik ilişkilerini analiz etmek için, Hacker ve Hatemi (2006) tarafından geliştirilen simetrik nedensellik testi ve zamanla değişen simetrik nedensellik testleri kullanılmıştır.

\section{Simetrik Nedensellik Testi}

Toda ve Yamamoto (1995) nedensellik testine dayalı olarak geliştirilen Hacker ve Hatemi (2006) simetrik nedensellik testinde serilerin durağan olması gerekmekte; ancak serilerin aynı mertebeden durağan olmasına ihtiyaç duyulmamaktadır. Bununla birlikte test istatistiklerinin bootstraba dayalı olması nedeniyle hata terimlerinin normal dağılmadığ durumlarda da tahmin sonuçları güvenilirliliğini kaybetmemektedir. Simetrik nedensellik testinde nedensellik ilişkilerini analiz etmek için aşağıdaki denklem kullanılmaktadır.

$$
y_{t}=\hat{v}+\bar{A}_{1} y_{t-1}+\cdots+\bar{A}_{p} y_{t-p}+\cdots+\bar{A}_{p+d} \bar{y}_{t-p-d}+\widehat{\varepsilon}_{t}
$$

Simetrik nedensellik testinde değişkenler arasında nedensellik ilişkisi bulunmadığını ifade eden $\mathrm{H}_{0}$ hipotezi, değişkenler arasında nedensellik ilişkisi bulunduğunu öne süren $\mathrm{H}_{1}$ alternatif hipotezine karşı sinanmaktadır. Test istatistiklerinin kritik değerlerden büyük olması durumunda $\mathrm{H}_{0}$ hipotezi reddedilmekte de değişkenler arasında nedensellik ilişkisi bulunduğu sonucuna ulaşılmaktadır.

\section{Zamanla Değişen Simetrik Nedensellik Testi}

Değişkenler arasındaki nedensellik ilişkileri zamana bağlı olarak değişebilmektedir. Ekonomik krizler, politika değişiklikleri ve siyasi istikrarsızlıklar değişkenler arasındaki nedensellik ilişkilerinin zaman içinde değişmesine neden olmaktadır. Bu bağlamda değişkenler arasındaki nedensellik ilişkilerinin zamana bağlı olarak değişip değişmediğini test etmek için Hacker ve Hatemi (2006) tarafindan geliştirilen simetrik nedensellik testinin zamanla değişen versiyonları kullanılmıştır. Zamanla değişen simetrik nedensellik analizlerinde ele alınan dönemler alt dönemlere ayrılarak, dönemler itibariyle nedensellik ilişkisinin değişip değişmediği analiz edilmektedir. Çalsşmada belirlenen pencere sayısı $17^{\prime}$ dir ve rolling window yöntemi kullanılmıştır. Alt dönemler 1990-2006, 1991-2007, 1992-2008, 1993-2009, 1994-2010, 1995-2011, $1996-$ 2012, 1997-2013, 1998-2014, 1999-2015, 2000-2016, 2001-2017 dönemlerinden oluşmaktadır. Öncelikle veri setinin tamamına Hacker ve Hatemi (2006) simetrik nedensellik testi uygulanır. Daha sonraki aşamada her alt dönem için ilk gözlem değeri atılarak, son gözlem değerine bir sonraki gözlem değerini eklemek suretiyle alt dönemlere Hacker ve Hatemi (2006) simetrik nedensellik testi uygulanır. Elde edilen Mwald test istatistikleri \%10 anlam seviyesinde elde edilen boostsrap kritik değerleriyle normalleştirilerek grafiğe aktarllır. MWALD istatistik değerlerinin grafikte yer alan 1 çizgisinin üzerinde kalması değişkenler arasında nedensellik ilişkilerinin var olduğu alt dönemleri göstermektedir.

\section{Bulgular}

Nedensellik analizlerinde, öncelikle serilerin durağan olup olmadığ1 test edilmeli, nedensellik analizleri durağan seriler kullanılarak yapılmalıdır. Bu bağlamda öncelikle serilerin durağanlığını sınamak için Zivot Andrews (1992) birim kök testi kullanılmıştır. Zivot Andrews birim kök testinde hipotezler

$\mathrm{H}_{0}$ : Seriler yapısal kırılmalar altında birim kök içermektedir

$\mathrm{H}_{1}$ : Seriler yapısal kırilmalar altında birim kök içermemektedir.

şeklindedir. Mutlak değerler itibariyle hesaplanan test istatistiklerinin kritik değerlerden büyük olması durumunda $\mathrm{H}_{0}$ reddedilir. $\mathrm{H}_{0}$ 'n reddedilmesi durumunda serilerin durağan olduğuna karar verilmektedir. Tablo 1 Zivot Andrews birim kök testi tahmin sonuçlarını vermektedir. 
Tablo 1. Zivot Andrews Birim Kök Testi Tabmin Sonuclar

\begin{tabular}{|c|c|c|c|c|c|c|c|c|}
\hline \multirow[b]{3}{*}{ Değişkenler } & \multicolumn{8}{|c|}{ Sabitli Model } \\
\hline & \multicolumn{4}{|c|}{ Düzey Değerleri } & \multicolumn{3}{|c|}{ Fark Değerleri } & \multirow[b]{2}{*}{ KARAR } \\
\hline & $\mathrm{ZA}$ & $\begin{array}{l}\text { Kritik } \\
\text { Değer }\end{array}$ & $\begin{array}{l}\text { Kurılma } \\
\text { Tarihi }\end{array}$ & KARAR & $\mathrm{ZA}$ & $\begin{array}{l}\text { Kritik } \\
\text { Değer }\end{array}$ & $\begin{array}{l}\text { Kurılma } \\
\text { Tarihi }\end{array}$ & \\
\hline Kanser Vakaları & -4.32 & & 2012 & $\mathrm{H}_{0} \mathrm{RED}$ & - & & 2003 & - \\
\hline Gelir & -2.39 & -4.08 & 1999 & $\mathrm{H}_{0} \mathrm{KABUL}$ & -5.21 & -4.08 & 2011 & $\mathrm{H}_{0} \mathrm{RED}$ \\
\hline Verimlilik & -4.64 & & 2004 & $\mathrm{H}_{0} \mathrm{RED}$ & -6.73 & & 2003 & - \\
\hline
\end{tabular}

Tahmin sonuçları incelendiğinde Kanserli hasta sayısı ve verimlilik değişkenlerinin düzey değerlerinde durağan olduğu; ancak gelir değişkeninin durağan olmadığ1 görülmektedir. Gelir değişkenini durağanlaştırmak için serinin birinci farkı alınmıştır. Fark serisi için elde edilen tahmin sonuçları incelendiğinde serinin durağanlaştı̆̆ görülmektedir. Bu bağlamda kanserli hasta sayısı ve verimlilik değişkenleri $\mathrm{I}(0)$ iken, gelir değişkeni $\mathrm{I}(1)$ 'dir. Serilerin durağanlık düzeyleri tespit edildikten sonra değişkenler arasındaki nedensellik ilişkilerini analiz etmek için simetrik nedensellik testi kullanılmıştır.

Tablo 2. Simetrik Nedensellik Testi Tabmin Sonuclar

\begin{tabular}{|c|c|c|c|c|c|}
\hline \multirow{2}{*}{ Nedenselliğin Yönü } & \multirow{2}{*}{ Test istatistiği } & \multicolumn{3}{|c|}{ Kritik Değerler } & \multirow{2}{*}{ KARAR } \\
\hline & & $\% 1$ & $\% 5$ & $\% 10$ & \\
\hline Kanser $\rightarrow$ Ulusal Gelir & 0.435 & 17.140 & 10.848 & 8.288 & $\mathrm{H}_{0}$ REDDEDİLEMEZ \\
\hline Kanser $\rightarrow$ Verimlilik & 4.491 & 16.041 & 9.966 & 7.532 & $\mathrm{H}_{0}$ REDDEDİLEMEZ \\
\hline
\end{tabular}

Simetrik nedensellik testi tahmin sonuçları incelendiğinde hesaplanan test istatistiklerinin kritik değerlerden küçük olduğu görülmektedir. Yani kanserli hasta sayısı ve verimlilik arasında ve kanserli hasta sayısı ile ulusal gelir arasında herhangi bir nedensellik ilişkisine rastlanmamıştır. Değişkenler arasındaki nedensellik ilişkilerinin zamana bağlı olarak değişip değişmediğini analiz etmek için zamanla değişen simetrik nedensellik testi yapılmıştır. Şekil 2 ve Şekil 3 zamanla değişen simetrik nedensellik testi sonuçlarını vermektedir.

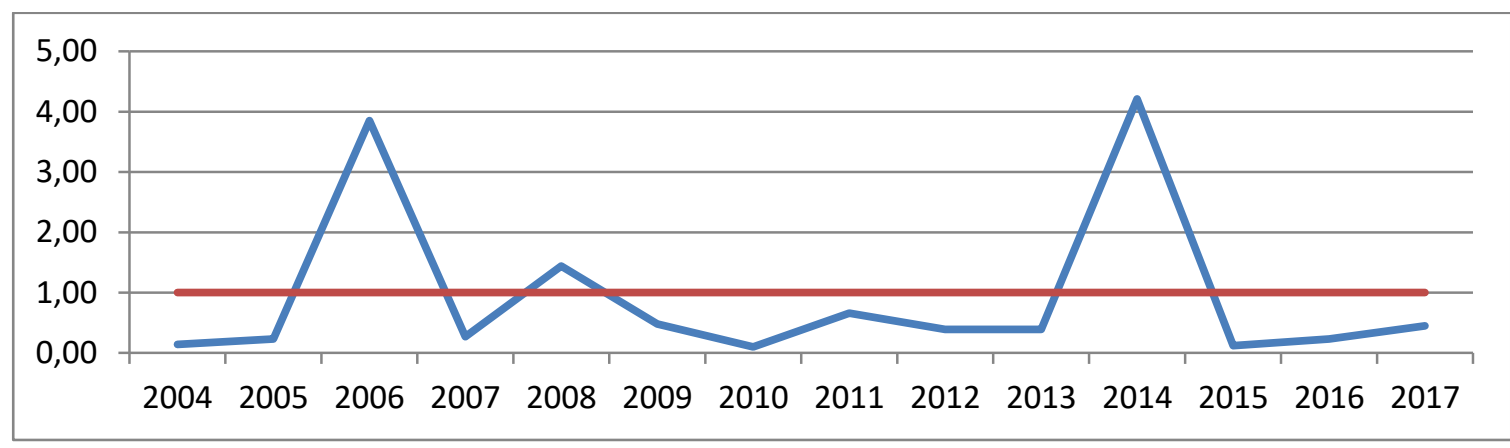

Şekil 2. Kanser Vakalar ve Ulusal Gelir Arasindaki Zamanla Değģsen Simetrik Nedensellik İlişkileri

Tahmin sonuçlarına göre 1990-2006 dönemi ile 1998-2014 dönemi kanserli hasta sayısı ile ulusal gelir arasında nedensellik ilişkisinin var olduğu dönemlerdir. Kanserli hasta sayısı ile verimlilik arasındaki zamanla değişken nedensellik ilişkileri incelendiğinde, 1992-2008 dönemi ile 2000-2016 dönemi kanserli hasta sayısı ile verimlilik arasında nedensellik ilişkisinin bulunduğu dönemlerdir.

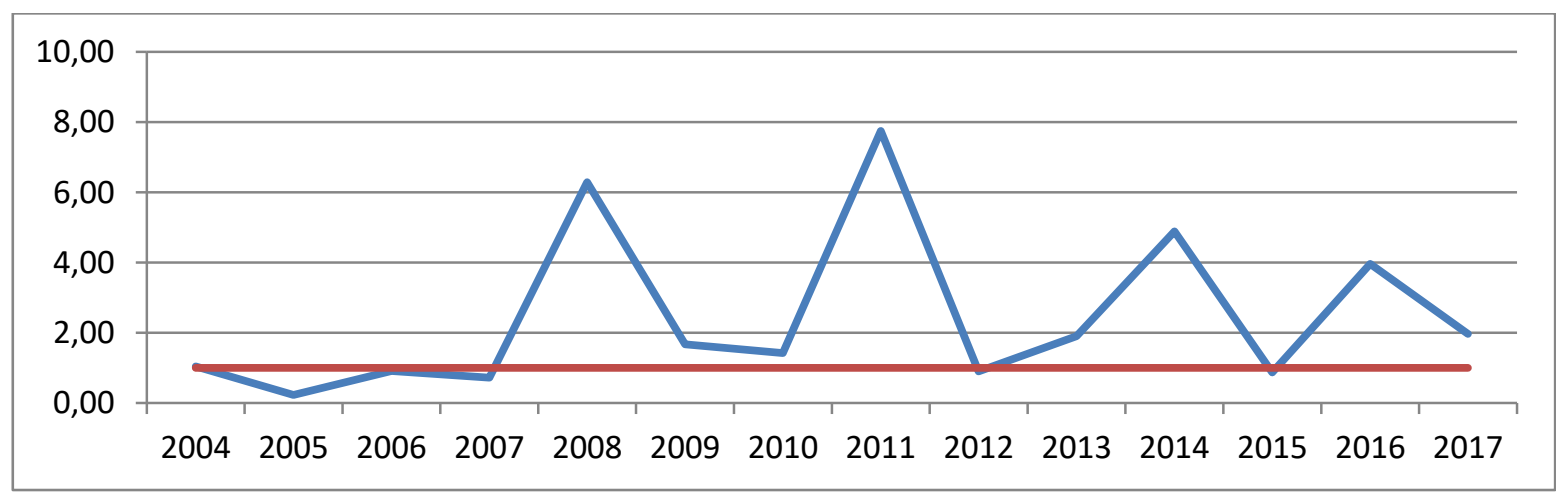

Şekil 3. Kanser Vakalar ile Verimlilik Arasındaki Zamanla Değģsen Simetrik Nedensellik Testi Tabmin Sonuclar 
Kanserli hasta sayısındaki artşsların emek verimliliğini azaltarak, ulusal gelir düzeyini negatif etkilemesi beklenmektedir. Elde edilen sonuçlar birlikte değerlendirildiğinde; 2000-2014 yılları arasında kanserli hasta sayısı ile verimlilik ve ulusal gelir düzeyi arasında nedensellik vardır denebilir. Bu dönemlerde değişkenler arasında nedensellik ilişkilerinin görülmesinde kanserli hasta sayısındaki artışla beraber, küresel piyasalardaki belirsizliklerin emek verimliliği ve ulusal gelir düzeyini azaltması da etkili olmuştur.

\section{Sonuç ve Değerlendirme}

Hastalık yükündeki artışların hem nicelik bakımından hem de nitelik bakımından emek stokunu ve dolayısıyla ulusal çıtı düzeyini olumsuz etkilemesi beklenmektedir. Türkiye'de hastalık yükü istatistikleri incelendiğinde, kanser insidansının her geçen gün arttı̆̆ı ve en çok ölüme sebep olan hastalıklardan biri olduğu gözlenmektedir. Bununla birlikte Sağlık Bakanlı̆̆ı tarafindan yapılan çalışmalarda, kanser insidansındaki artışın devam etmesi halinde kanser tedavi maliyetlerinin Sağlık Bakanluğı tarafindan karşılanamayacak boyutlara ulaşması beklenmekte ve koruyucu ve önleyici sağlık politikalarının gerekliliği vurgulanmaktadır. Bu bağlamda 1990-2017 dönemini kapsayan bu çalışmada kanserli hasta sayısı ile emek verimliliği ve ulusal çıtı düzeyi arasındaki nedensellik ilişkileri simetrik ve zamanla değişen simetrik nedensellik testleri kullanılarak analiz edilmiştir. Simetrik nedensellik testi sonuçlarına göre kanserli hasta sayısı ile emek verimliliği ve ulusal çıktı düzeyi arasında herhangi bir nedensellik ilişkisi bulunmazken, zamanla değişen simetrik nedensellik testi sonuçlarına göre, 1990-2006 dönemi ile 1998-2014 dönemlerinde kanserli hasta sayısı ile kişi başına düşen ulusal gelir düzeyi arasında nedensellik ilişkisi görülürken, 1992-2008 dönemi ile 2000-2016 dönemlerinde kanserli hasta sayısı ile emek verimliliği arasında nedensellik ilişkisi vardır. Kanserli hasta sayısındaki artışların emek verimliliğini azaltarak, ulusal gelir düzeyini etkilemesi beklenmektedir. Bu bağlamda 2000-2014 yılları arasında kanserli hasta sayısı ile verimlilik ve ulusal gelir düzeyi arasında eş anlı nedensellik bulunmaktadır. Eş anlı nedenselliğin bu dönemde ortaya çıkmasında kanserli hasta sayısındaki artışla beraber, küresel krizin ve piyasalarda hakim olan belirsizliklerin emek verimliliği ve ulusal gelir düzeyini azaltmış olmasının da etkili olduğu söylenebilir.

\section{Etik Beyan}

"Hastalılar, Verimlilike ve Ulusal Gelir Arasindaki Nedensellik İliskilerinin Analizi: Türkiye'de Kanser Örneğğ" başlıklı çalışmanın yazım sürecinde bilimsel, etik ve alıntı kurallarına uyulmuş; toplanan veriler üzerinde herhangi bir tahrifat yapılmamış ve bu çalışma herhangi başka bir akademik yayın ortamına değerlendirme için gönderilmemiştir.

\section{Kaynakça}

Afsa, C.ve Givord, P. (2002) The impact of working conditions on absenteeism. http:// www.crest.fr/ckfinder/userfiles/files/pageperso/givord/labour_economics.pdf(Erişim Tarihi : 11.06.2019)

Amir Z., Moran A., Wals L., Iddenden R. ve Luker, K. (2007). Return to paid work after cancer: a British experience.TheJournal of CancerSurvival, 1(2): 129-36.

Arozullah, A. M, Calhoun, E. A., Wolf, M., Finley, D.K., Heckinger, E. A., Gorby, N.S., Schumock, G.T. ve Bennett, C. L. (2004). The financial burden of cancer: estimates from a study of insured women with breast cancer. The Journal of Support Oncology, 2(3), s.271-278.

Bloom, D. veCanning, D. (2008). Population bealth and economic growth. World bank Working Paper No: 24, Washington.

Case, A.veDeaton, A. (2005). Broken: how our health declines. National Bureau of Economic Research, University of Chicago Press.

Cuddington, J. (1993). Modeling the macroeconomic effects of AIDS, with an application toTanzania. The World Bank Economic Review, 7, 173-189.

Çakır Edis, E. ve Karlıkaya, C. (2007). The cost of lung cancer in Turkey. Tüberküloz ve Toraks Dergisi, 55(1): 51-58.

Daly, K. (2000). The business response to HIV/AIDS: impact and lessons learned. World Bank, Geneva and London.

Ekwueme, D. U., Trogdon, J. G., Khavjou, O. A. ve Guy, G. P. (2015). Productivity costs associated with breast cancer among survivors aged 18-44 years. American Journal of Preventive Medicine. Volume 50, Issue 2, 286-294.

Ertan A. E. (2003). Hacettepe Üniversitesi Erişkin Hastanesinde į̨lenen bą̧ akciğer hastalarmm tam ve tedavi sağhk harcamalar. Basılmamış Tıpta Uzmanlık Tezi. Hacettepe Üniversitesi: Ankara.

Hacker, S.R. veHatemi-J, A. (2006). Tests for causality between integrated variables using asymptotic and bootstrap distributions: theory and application. Applied Economics, 38, 1489-1500

Hanly, P. A. ve Sharp, L. (2014). The cost of lost productivity due to prematüre cancer-related mortality: an economic measure of the cancer burden. BMC Cancer, 14:224,1-10.

Hanly, P., Timmons, A., Walsh, P., ve Sharp, L. (2012). Breast and Prostate Cancer Productivity Costs: A Comparison of Human Capital Approach and the Friction Cost Approach. Value in Health. Vol.15, Issue 3, 429-436. 
Koçkaya G., Polat M., Wertheimer A. I., Özet A, Malhan S., Vural İ. M., Akbulat, A., Artıran G., Gürsöz H. ve Kerman S. (2013). Treatment cost of meta static colon cancer in Turkey. Farmeconomia. Health Economics and Therapeutic Pathways. 14(1):19-25.

Mahal, A., Karan, A. Fan, V. Y. Ve Engelgau, M. (2013). The economic burden of cancers on Indian households. Asia Pacific Journalof Cancer, 9,. 671-677.

Özmen V., Gürdal, S. Ö., Cabioğlu, N., Özçınar, B., Özaydın, A. N., Kayhan, A., Arıbal, E., Şahin, C., Saip, P. ve Alagöz, O. (2017). Cost-effectiveness of breast cancer Screening in Turkey, a developing country: results from. Bahçeşehir Mammography Screening Project.

Pearce, A., Sharp, L., Hanly, P., Barchuk, A., Bray, F., Cancela, M., Gupta, P., Meheus, F., Qiao, Y., Sitas, F., Wang, S. ve Soerjomataram, I. (2018). Productivity losses due to prematüre mortality from cancer in Brazil, Russia, India, China and South Africa (BRICS): a population-based comparison. Cancer Epidemiology. 53, 27-34.

Stenier, J. F., Tia, C.A, Main, D. S. ve Bradley, C. J. (2004). Assessing the impact of cancer on work out comes. Cancer, Volume :101, Number :8, s.1703-1711.

Toda, H.Y. ve Yamamoto, T. (1995). Statistical inference in vector autoregressions with possibly integrated processes. Journal of Econometrics, 66(1-2), 225-250.

Torun, P. ve Kutlar, A. (2018). Türkiye'de kanserin ekonomik maliyetleri: bir hesaplanabilir genel denge modeli. Hacettepe Üniversitesi Sağllk İdaresi Dergisi, 21(1), 87-101.

Venkatesan, P. (2018). Cancer-related productivity losses in BRICS countries. The Lancet Oncology, Volume:19, Issue: $3,147-149$.

World Bank (2001). World development report attacking poverty. Newyork: Oxford University Press.

Yazıhan N. ve Yılmaz, H. H. (2007). Türkiye'de Kanser Kontrolü. İçinde: Tuncer M.(Edt.) Türkiye'de meme kanseri: ekonomik etkinlik ve maliyet etkililike (ss.363-375) Ankara: T.C. Sağlık Bakanlığı Kanserle Savaş Dairesi Başkanlığ1.

Zivot, E. ve Andrews, D. W. K. (1992). Further evidence on the great crash, the oil price shock, and the unit-root hypothesis. Journal of Business \&Economic Statistics 10(3): 251-270.

\section{EXTENDED ABSTRACT}

Macroeconomic and microeconomic effects of diseases are examined within the scope of literature on economic costs of diseases both in terms of resource allocation and their effects on economic decision-making units. Disease costs are divided into two as direct and indirect costs. Indirect costs include the negative effects of diseases on production and national income while direct costs mean the amount of money allocated for the treatment of diseases. In this context, disease burden surveys are carried out.

Diseases adversely affect the national income level through the decrease in life expectancy, the decline in child investments due to the increase in infant and child mortality and the decrease in individual labor productivity (World Bank, 2001).

Cuddington (1993) emphasizes that increases in morbidity rates negatively affect labor productivity. Thereby, they reduce non- health goods and service consumption by increasing individual health expenditures and thus individuals' saving behavior will change and the national income will decrease.

The diseases have a negative effect on also human capital stock and education level and the education is main determination of human capital. However, health level also affects education level and rate of attendance to lesson significantly. Consequently, the diseases reduce human capital stock by negatively affecting students' cognitive functions.

Depending on health status the diseases, the diseases also affect the attendance of the employees, the income and profitability of the companies. They have an effect labor turnover, business knowledge and ability and work motivation. While disease have negative impact on labor supply by reducing employee's ability and motivation to do work, increasing the amount of resources allocated for the recruitment and training of a new worker increases the company costs. In this context, the diseases can have negative effects on the company's level of production and profitability of the company.

The cost of the resources allocated to the treatment of diseases to the individual and the firms depend on the level of development of health insurance in the country and the scope of health insurance. In addition, the increase in the amount of resources allocated for the treatment of diseases can reduce the investment opportunities in more productive areas and may have an effect on disrupting the effective resource allocation.

When the data of the Ministry of Health is examined; cancer incidence and prevalence of cancer in Turkey is seen that day by day increases. According to research conducted by the Ministry of Health, 
unless preventive health measures are taken, the expenditures made for cancer treatment in the 2030's are expected to reach the extend that cannot be covered by the budget of the Ministry of Health.

Diseases negatively affect also the human capital stock in terms of quality through labor productivity while they have a negative effect on the labor stock due to their mortally. In addition to, the increase in the amount of resources allocated for the treatment of diseases may have an effect on disrupting the efficient distribution of resource by reducing the investment opportunities in more productive areas. Studies on the direct costs of cancer in Turkey is made. However, the number of studies on the indirect effects of cancer is limited. In this context, the purpose of this study is to analyze the causality relationships between diseases, labor productivity and the national income for the period of 1990-2017. Symmetric Causality Test and Time Varying Causality Test were used in the study. The number of cancer patients, labor productivity index and per capita income are variables used in the model. The number of cancer patients was obtained from the world cancer research fund statistics. Output levels per working hour and national income statistics per capita are obtained from the OECD database. The output level per working hour was used as an indicator of labor productivity.

In the causality analysis, first of all, stationary of series should be tested and the causality analysis should be done by using stationary series. In this context, Zivot-Andrews unit root test was used to test stationary of the series. According to results of unit root test, the number of cancer patients and productivity variables are I (0), but; income variable is I (1).

According to results of Time Varying Symmetric Causality Test, there is causality relationship between the number of in periods of 1990-2006 and 1998- 2014 and there is causality relationship between the number of cancer patient and labor productivity periods of 1992-2008 and 2000-2016.

The period of 2000-2014 is periods when there is a simultaneous causality between the number of cancer patient, the labor productivity and the percapita national income. 